\title{
Organizing a portfolio of projects to ensure the required energy efficiency
}

\author{
David Sarkisov ${ }^{1, *}$ and Maksim Esenov ${ }^{1}$ \\ ${ }^{1}$ Moscow State University of Civil Engineering, Yaroslavskoe shosse, 26, 129337, Moscow, Russia
}

\begin{abstract}
The subject of this paper is the study of the use in practice of the components of the project portfolio in optimal condition. An important issue in the study of this project is the evaluation of the effectiveness of these components. Attention is paid to the portfolio of projects where it is possible to carry out continuous restructuring in accordance with the limited investment opportunities. The authors have developed energy-efficient methods of project management and control at all stages of construction. The role of the utility function in the formation of the investment portfolio is also considered. A model for calculating the indicators of the project portfolio is developed on the example of building a network of banks in Russia. This model allows you to avoid financial losses, evaluate your activities, and improve the efficiency and effectiveness of projects.
\end{abstract}

\section{Introduction}

In today's competitive market, it is not enough to complete individual projects, but it is necessary to complete all projects in the company. The success of the company will depend not only on the implementation of existing projects and proper work on them, but also on how well these projects will be selected. It is also necessary to allocate available resources optimally and efficiently, depending on the priority of projects [1]. This trend of project management is called project portfolio management. The project portfolio essentially acts as a collection of technologically independent projects. At the same time, they are combined together and implemented by the organization in order to achieve strategically important indicators and improve management efficiency [2].

Project financing is characterized by the presence of certain principles, which include the following:

\section{Differentiation}

This principle implies an optional unambiguity in resolving the problem of financing the project by its participants. The ability to finance a project should be influenced by factors such as the economic feasibility of the project, as well as its viability.

The economic feasibility of the project is reflected in the payback period within the agreed and acceptable terms for investors. The viability of the project is determined by the ability of the project company to meet its debt obligations in a timely manner.

2. Intended use

\footnotetext{
${ }^{*}$ Corresponding author: dav9.9@mail.ru
} 
This principle assumes a strict concentration of the received financial resources on certain goals set by the project participants. In other words, the implementation of the project involves the formation of a new business and the receipt of cash flows that will provide debt obligations in the future. In accordance with this, any deviations in the use of financial resources from the established goal of the project can negatively affect the further viability of the project, that is, as already indicated, the ability to meet its obligations, as well as to increase its own capital.

\section{Risk allocation}

The principle of risk allocation allows the most rational division of the consequences of the occurrence of a particular risk in the course of the project between the participants. This means that responsibility is shared among all project participants, which allows for more effective risk management. For example, if the construction period is exceeded, the contractor is responsible for it. And if changes were made to the estimate, and the project faced a lack of financial resources, the initiator of the project, etc., is responsible for this.

4. Profitability

If we consider it from the perspective of the lender, the principle of profitability is the principle of payment (payment of a certain amount by the borrower for the use of the provided funds for a certain period). From the point of view of the borrower, it can be indicated that the payment of the loan acts as an additional incentive for the most rational and effective use of borrowed funds. The principle of profitability of the project is determined by the ability of the investor to maximize the profit from the invested funds in the project, including borrowed ones.

\section{Isolation}

The principle of project isolation is reflected in the fact that the implementation of the project requires its economic and legal isolation from the standard activities of the organization. The legal isolation lies in the fact that at the initial stage, a project company is immediately formed, which is responsible for the implementation of the project. From the point of view of economic isolation, it should be emphasized once again that the debt obligations will be provided not by the assets of the organization, but by the cash flows generated during the project itself. Isolation in many ways allows you to distinguish between the risks inherent in a particular project, and in accordance with this, to form a certain structure of financing. In addition, it allows you to avoid the influence of extraneous factors (related to the standard activities of the company and its existing debt obligations) on making a profit during the implementation of the project.

6 . The predominance of the importance of cash flow over assets

This principle is based on the economic isolation of the project and the ability of the project to be independently responsible for debt obligations through the generated cash flows, rather than the assets of the company.

There are various methods of project management that allow companies to assess the priority of projects, the effectiveness and efficiency of their implementation within the company as a whole [3]. As a result, it is possible to improve the project implementation process and improve management efficiency. Project management methods and tools provide the necessary control of the project at all stages and its implementation in a timely manner. The project portfolio is constantly reviewed and refined, depending on the company's strategic goals or changes in the market [5]. New projects can be added to the portfolio, which can also completely replace the old ones, which will increase the usefulness of the portfolio.

With a limited investment capital of a firm, it is extremely important to correctly determine the project portfolio in order to avoid financial losses, get income from projects, evaluate its activities, management, and increase the effectiveness and efficiency of projects. 
In this paper, we will consider methods for selecting the optimal portfolio of projects with limited investment capital.

\section{Materials and methods}

Managing a portfolio of projects includes:

1. Exploring potential projects

2. Selection of projects to be implemented

3. The initiation of projects, i.e. the formal recognition of the project

4. Project planning and operations management

5. Technical proposal development

6. Budgeting projects

7. Project execution

8. Reporting and control

9. The completion and closure of projects

10. Improvement and updating of processes and management methods [4].

The investment capital of the company can include: financial resources, buildings, working equipment, intellectual resources, i.e. what the company can invest in the project, the funds that will be used for its execution.

Investment capital can be of two types: own (retained earnings, depreciation charges) and borrowed, the source of which is temporarily free other people's money [5].

Often, a firm's investment capital consists of its own resources. The task arises of setting project priorities based on which resources will be allocated between projects. But even if priorities are set correctly, there may not be enough resources for all projects. In this situation, there is a problem of choosing projects to form an optimal portfolio. When selecting projects, it is important to consider its relevance to the company's strategy, cost-effectiveness, timing and quality of project implementation [6].

Single-criteria models for making decisions about selecting projects for a portfolio based on unknown factors can be divided into deterministic models (the method of solving the problem is defined unambiguously as a sequence of steps, no ambiguities or uncertainties are allowed at any step), stochastic (random) models, and models with elements of uncertainty [7].

Existing models of portfolio formation that are implemented in conditions of certainty, as well as depending on the type of target function and restrictions, can be divided into four types (fig.1):

1. Linear

2. Non-linear

3. Dynamic

4. Graphical

Optimizing a portfolio of projects, three tasks are going to be solved:

1. Project selection, i.e. combining separate independent projects, the implementation of which will be aimed at achieving the company's goals, forming new ideas, and improving the quality of project management.

2. Development schedule project execution

3. Alignment of projects to optimize resource loading [8].

In the case of limited investment capital, in the case of limited resources, these points are the most important. The portfolio of projects to achieve efficiency indicators should contain only the projects most favorable to the enterprise, and they perfectly match the resources 
constraints and the strategic goals of the organization. The most universal and frequently used in practice is the method of summary indicators [9].

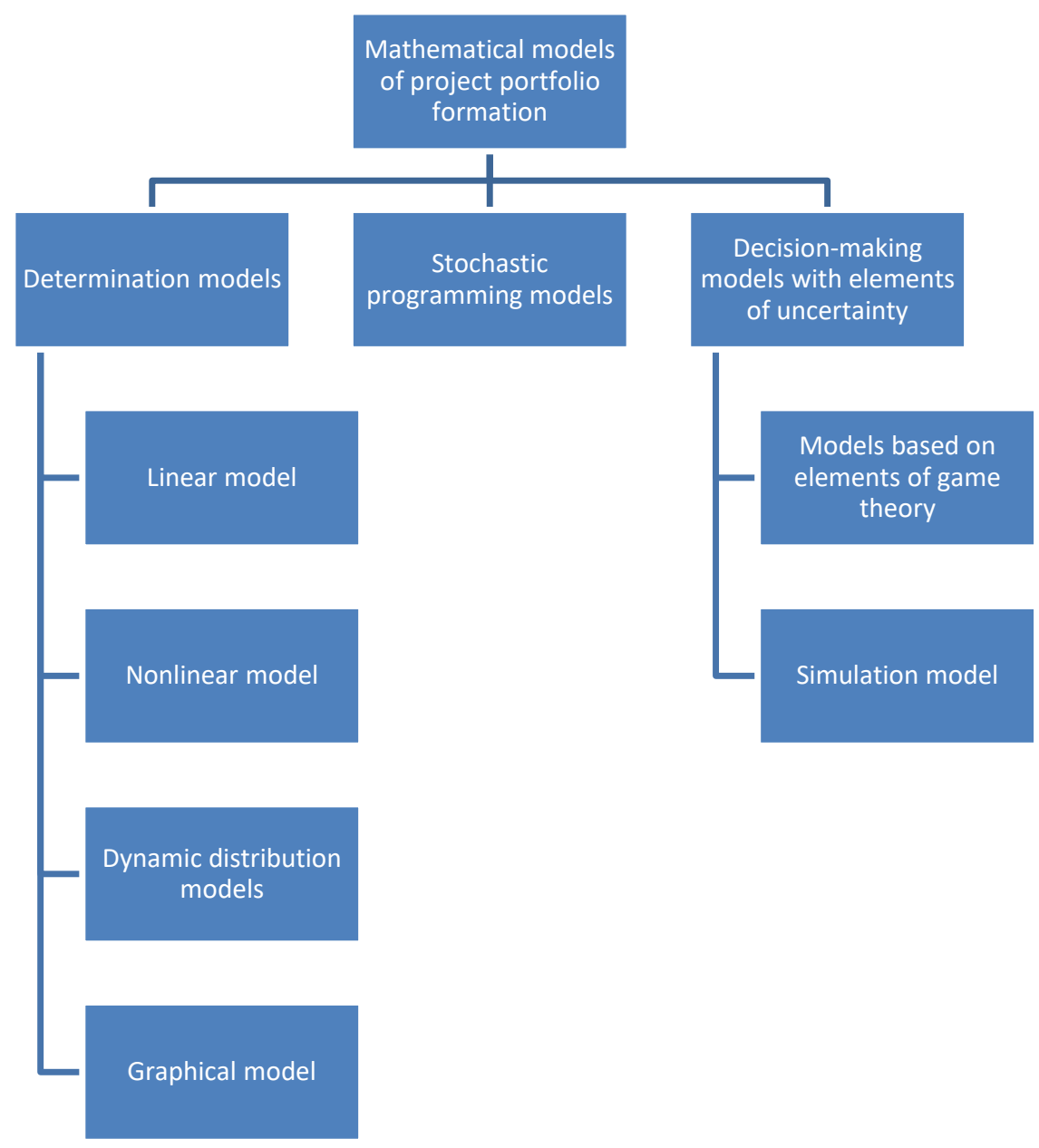

Fig. 1. Classification of single-criteria models of project portfolio formation.

\section{Results}

As an example, consider the project of creating a network of several banks on the territory of the Russian Federation. Accordingly, the problem of choosing the best geographical locations in terms of building the company's strategic goals.

In accordance with the method of summary indicators, a sequence of calculations is proposed:

1. Definition of the target functions of the program implementation:

As you can see, we have identified the main target function, which allows us to judge the acceptability or unacceptability of a given geographical point in terms of compliance with the strategic goals of the enterprise: 
A. investment goals are directly related to the indicator of investment activity in the region. They take into account the indicator of investment activity and the security of doing business.

B. technological goals should correspond to the assessment of the situation in this region according to a successfully functioning bank

C. financial goals are aimed at reducing the cost of creating the entire network, and therefore, an individual bank in particular [9]:

The developed method of selecting location points is designed to evaluate each geographical point in terms of the three main indicators and then combine them into an integral indicator:

- Maximizing the integral index for the function A;

- Maximizing the integral index for function B;

- Reduce the integral indicator using the function [9].

2. At this stage, it is important to determine the parametric characteristics of the assessment of the geographical location of banks. The parameters for each of the three target functions can be grouped as follows:

A. indicators related to the population of the region and their income.

B. parameters related to banks: size, segment of the bank.

C. indicators related to the bank construction project in region.

3. at this stage, the parameters are classified: they are classified as quantitative or qualitative. When evaluating the quality criteria, you can use the Harington desire function, the values of which are calculated using the following formula:

$$
a_{i}=\operatorname{Exp}\left(\left(-\operatorname{Exp}\left(\left(-y_{i}\right)\right)\right.\right.
$$

$a_{i}$ is the value of the desired function

$y_{i}$-the value of parameter I.

4. determination of the degree with the obtained parameters.

At this stage, the assessment of the expert community is usually used.

5.an important step to get an essential parameter is to correctly determine the weight factors for each parameter of the target function.

The weight of the coefficient must take into account the contribution of the parameter to the integral indicator. For a correct assessment, it is advisable to use the following formula:

$$
W_{i}=(2(N-i+1)) /(N(N+1)), i=1,2, \ldots, N
$$

The function in this case is a logistic curve. The interval of which is set by the segment $(0,1)$. It is used as a non-uniform scale, also called the desirability scale, for evaluating parameter levels.

6. At this stage, the quantitative and qualitative parameter of the geographical point is estimated using the objective function.

In order to put together a large number of characteristics that are assigned different weights, have different characteristics and sizes, it is worth building a system of individual indicators that can normalize the initial characteristics. For simplicity, we will limit ourselves to the consideration of linear normalizing functions.

For indicators that increase the attractiveness of a geographical point (population purchasing power), a monotonously increasing form function will be used: 


$$
q_{k}^{l}\left(x_{k}^{l}\right)=\left\{\begin{array}{c}
0, x_{k}^{l} \leq \min _{k} \\
x_{k}^{l}-\min _{k} \\
\max _{k}-\min _{k} \\
1, x_{k}^{l}>\max _{k}
\end{array}, \min _{k}<x_{k}^{l} \leq \max _{k}\right.
$$

$q_{k}^{l}\left(x_{k}^{l}\right)$ - is the normalized index of the $\mathrm{k}$ parameter of the 1 region,

$\min _{k}\left(\max _{k}\right)$ - the minimum (maximum) value of the $\mathrm{k}$ parameter for all sample regions,

$$
l \in(1-N), k \in K^{1}
$$

K1-represents the set of parameter indices that are given by monotonically increasing functions.

For those indicators that are factors that reduce the attractiveness of a geographical point (the cost of land, the cost of construction), a monotonically decreasing function of the form is used:

$$
q_{k}^{l}\left(x_{k}^{l}\right)=\left\{\begin{array}{c}
1, x_{k}^{l} \leq \min _{k} \\
\max _{k}-x_{k}^{l} \\
\max _{k}-\min _{k} \\
0, x_{k}^{l}>\max _{k}
\end{array}, \min _{k}<x_{k}^{l} \leq \max _{k}\right.
$$

$k \in K^{2}, K^{2}$ - is the set of parameter indices defined by monotonically decreasing functions.

$$
\left\{\begin{array}{l}
K^{1} \cap K=\varnothing \\
K^{1} \cup K^{2}=K
\end{array}\right.
$$

$K$ - all the set of parameter indexes used for estimating a geographical point.

7. The calculation of composite indicators for objective functions.

The individual indicators obtained are collapsed to the corresponding summary indicators, taking into account their significance:

$$
\begin{aligned}
& S P I P^{l}=\sum_{k \in I} w_{k} q_{k}^{l} \\
& S P O P^{l}=\sum_{k \in O} w_{k} q_{k}^{l} \\
& S P F P^{l}=\sum_{k \in F} w_{k} q_{k}^{l}
\end{aligned}
$$

$S P I P^{l}$ - is a summary indicator of the investment attractiveness of the 1 region (summer parameter of investment preference)

$S P O P^{l}$ - is a summary indicator of the attractiveness of the 1 region in terms of operating conditions (summer parameter of operating preference)

$S P F P^{l}$ - is a summary indicator of the financial attractiveness of the 1 region (summer parameter of financial preference)

$w_{k}$ - are weight coefficients that determine the significance of the $\mathrm{k}$ characteristic,

$$
\sum_{k \in I} w_{k}=\sum_{k \in O} w_{k}=\sum_{k \in F} w_{k}=1
$$

I, O, F-indices of indicators that characterize the investment, operational and financial attractiveness of the region, respectively [10]. 
8. Next, we calculate the integral indicator.

After getting the summary indicators from step 7, the integral indicator is calculated. The formula is shown below.

$$
S P T P^{l}=\omega_{1} S P I P^{l}+\omega_{2} S P O P^{l}+\omega_{3} S P F P^{l}
$$

$S P T P^{l}$ - is a summary indicator of the attractiveness of the i region (summer parameter of total preference)

$\omega_{1}$ - weight coefficients that determine the significance of each objective function for decision-making.

$$
\sum_{i=1}^{3} \omega_{i}=1
$$

9. The next step is to identify those objects that most fully correspond to the integral indicator. That is, these are the locations of banks whose integral indicator is higher than the critical value:

$$
\left\{l \in 1 \div N / S P T P^{l} \geq \min \right\}
$$

min - is the minimum value of the summary indicator set by the decision maker.

As a result of calculations using the proposed algorithm, the following sequence of regions was obtained, ordered by the degree of business preference (table 1).

Table 1. Summary ratings of regions.

\begin{tabular}{|c|c|c|}
\hline № & Region & SPTP \\
\hline 1 & Moscow & 0,74 \\
\hline 2 & Saint Petersburg & 0,57 \\
\hline 3 & Yekaterinburg & 0,49 \\
\hline 4 & Novosibirsk & 0,46 \\
\hline 6 & Moscow Region & 0,43 \\
\hline 7 & Tver region & 0,37 \\
\hline
\end{tabular}

\section{Conclusions}

In accordance with the results obtained, it was decided to make capital investments in the regions of the Russian Federation as part of the construction of projects for the development of a network of banks in Moscow, St. Petersburg, Yekaterinburg, and Novosibirsk. The developed model evaluates, in the course of analysis, a group of criteria that determine the specifics of the work of a particular organization.

\section{References}

1. J. Xiaohua, Z. Guomin, L. Junxiao, F. Yingbin and Z. Jian, Major Participants in the Construction Industry and Their Approaches to Risks: A Theoretical Framework, Procedia Engineering 182, 314-320 (2017) https://doi.org/10.1016/j.proeng.2017.03.100

2. T. Toth, Z. Sebestyen, Time-varying Risks of Construction Projects, Procedia Engineering 123, 565-573 (2015) https://doi.org/10.1016/j.proeng.2015.10.109 
3. S. Winge, E. Albrechtsen, J. Arnesen, A comparative analysis of safety management and safety performance in twelve construction projects, Journal of Safety Research 71, 139-152 (2019) https://doi.org/10.1016/j.jsr.2019.09.015

4. M. AbouHamad, M. Abu-Hamd, Framework for construction system selection based on life cycle cost and sustainability assessment, Journal of Cleaner Production 241, 118397 (2019) https://doi.org/10.1016/j.jclepro.2019.118397

5. A. Wei, C. Niu, B. Xia, Y. Dou, X. Hu, A refined selection method for project portfolio optimization considering project interactions, Expert Systems with Applications 142, 112952 (2020) https://doi.org/10.1016/j.eswa.2019.112952

6. S. Song, F. Yang, Q. Xia, Multi-criteria project portfolio selection and scheduling problem based on acceptability analysis, Computers \& Industrial Engineering 135, 793799 (2019) https://doi.org/10.1016/j.cie.2019.06.056

7. P. Szymanski, Risk management in construction projects, Procedia Engineering 208, 174-182 (2017) https://doi.org/10.1016/j.proeng.2017.11.036

8. M. Martinsuo, J. Gerald, Management of project portfolios: Relationships of project portfolios with their contexts, International Journal of Project Management 38, 441-453 (2020) https://doi.org/10.1016/j.ijproman.2020.02.002

9. A. Yang, K. Lee, S. Li, A mixed activity-based costing and resource constraint optimal decision model for IoT-oriented intelligent building management system portfolios, Sustainable Cities and Society 60, $102142 \quad$ (2020) https://doi.org/10.1016/j.scs.2020.102142 